\title{
Giving Patients Choice and Control: Health Informatics on the Patient Journey
}

\section{B. Gann}

NHS Choices, Department of Health, Skipton House, Elephant and Castle, London, United Kingdom

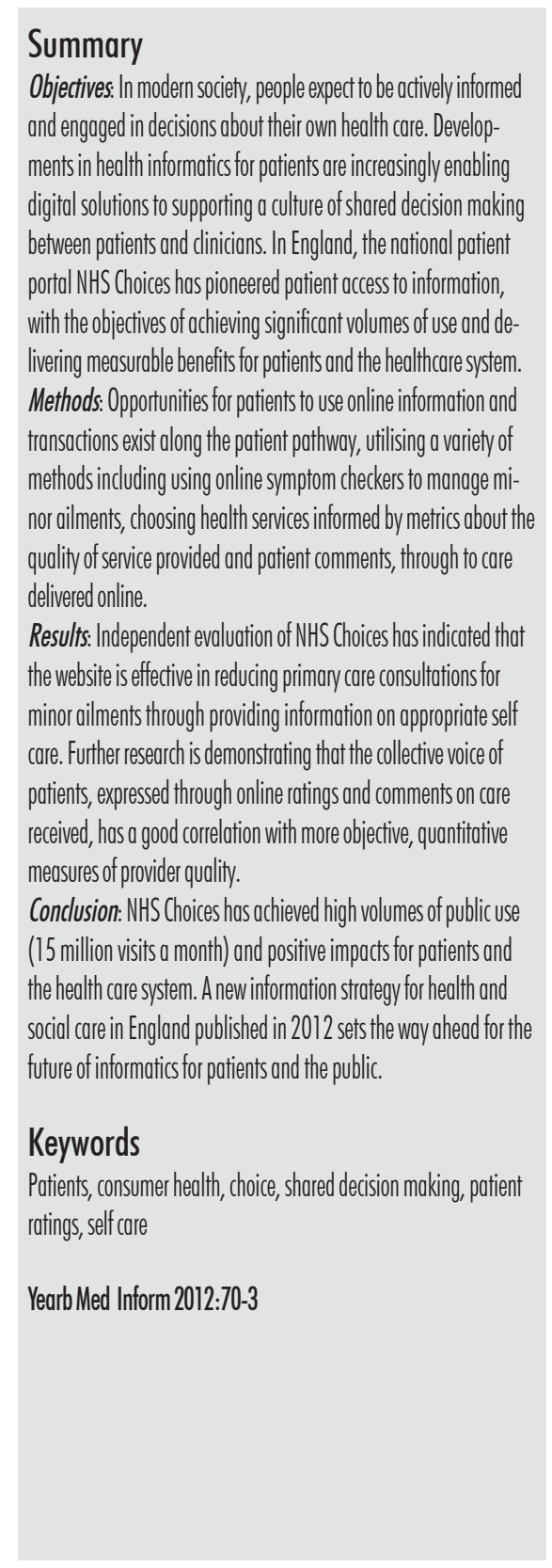

\section{Introduction: Public Expectation and Demand}

In twenty-first century society, people increasingly expect to be informed, involved and actively engaged in all aspects of their everyday lives. Health is no exception. Recent research by the UK consumer body Which? has demonstrated the appetite for health information. Over $70 \%$ of patients use the internet to search for information on their health [1] This is consistent with US studies carried out by Google [2] and Pew Research [3].

However Which? research [4] also suggests that, overall, the quality of online health information is rated poorly. Customer satisfaction with health information is low compared with travel, financial services or utlities. Often consumers are confused by the range of information available. Based on this research Which? recommends:

- People want a range of information formats to reflect different needs and approaches

- Interest in detail of information increases with seriousness or complexity of condition

- Factual information needs to be up to date, personalised, simple and comparable with a click through option for those who want more detail

- There should be access to online health information through authoritative portals

\section{Positive Outcomes from Shared Decision Making}

Although there is some evidence of adverse consequences [5] of patient use of information from the internet, on balance and in the right circumstances, the impacts are positive. This is particularly strong where information is provided through structured, personalised tools such as shared decision aids, which present the risks and benefits of treatment options in formats which patients can understand. The major systematic review of randomised controlled trials of decision aids [6] found that use of shared decision aids led to:

- greater patient knowledge

- more accurate perception of risk

- greater comfort with treatment decisions

- greater participation in decision making

- fewer people remaining undecided

- no increase in anxiety

- fewer patients choosing major surgery [7]

There is also evidence on the positive impacts of online health information and tools on behaviour change towards healthier lifestyles. The most extensive systematic review of published evidence [8] analysed studies into use of web-based health information and tools and concluded that these did on average lead to positive effects on health related behaviour. The effectiveness was greater where information is en- 
hanced by other methods (eg SMS text reminders) or interactive tools which build longer term engagement.

\section{No Decision About Me Without Me}

In England this societal trend is now reflected strongly in government policy, with a commitment to patient choice and control. Government policy as set out in Liberating the NHS [9] makes the commitment "Shared decision making will be the norm: no decision about me without me. Patients will have access to the information they want to make choices about their healthcare. Our aim is to give people access to comprehensive, trustworthy and easy to understand information from a variety of sources on conditions, treatment, lifestyle choices and how to look after their own and their family's health".

In a major public consultation on the Information Revolution [10] carried out in 2010-11, patient organisations, clinical bodies and the informatics industry were asked what they would like to see happen to deliver this information revolution. Many responses to the Information Revolution consultation supported the need for greater use of information to support choice, shared decision making and greater partnership. A number of respondents set out the types of information that are helpful in making choices. A typical response was "You need information about your condition, how it progresses, what treatments are available, their side effects, likelihood of success and timing" (patient/service user).

\section{Starting the Patient Journey: Search}

Most people, when seeking information on health, start with Google. $80 \%$ of all visits to the UK National Health Service portal, NHS Choices [11], come through Google. Google's own research [12] suggests that when faced with a symptom:

- $75 \%$ of patients research their condition online before seeing doctor

- And $70 \%$ go online afterwards to learn more

The problem here is not lack of information but of over-supply of highly variable quality. When seeking information about keeping well or coping with illness, patients have thousands of potential information sources - including NHS, patient organisations, commercial bodies. A UK Google search on "diabetes" produces $70 \mathrm{~m}$ results of varying quality, including high quality sites such as NHS Choices and Diabetes UK but also commercial sites selling herbal remedies and insurance policies.

The National Health Service has developed approaches to quality assurance including the Information Standard [13] and Information Prescriptions [14]. However these approaches are resource intensive for information producers and have not achieved high levels of take up.
As patients are likely to click on sites which appear high on Google search results (often nor going beyond the first page) NHS Choices has put considerable effort into the structuring and metadata of the website to optimise for best search engine results. This search engine optimisation has ensured high Google rankings for NHS Choices site for all major health conditions. A better Google ranking does not necessarily mean the site is of higher quality but the combination of trust in the NHS brand and appearing first in search results has been effective in driving traffic to NHS Choices rather than lower quality sites.

NHS Choices is, of course, only one of a number of high quality English language sites available for patients and the public. These include major international sites such as WebMD and Medline Plus, as well as excellent sites from patient organisations. However, NHS Choices has achieved scale because it is visibly part of the valued National Health Service, carries no advertising or sponsorship, and acts as a single online point of contact to a wide range of information and transactions (eg appointment bookings).

\section{Understanding Health Conditions}

The NHS Choices website provides a comprehensive portal for patients in England, funded by the government through national taxation. NHS

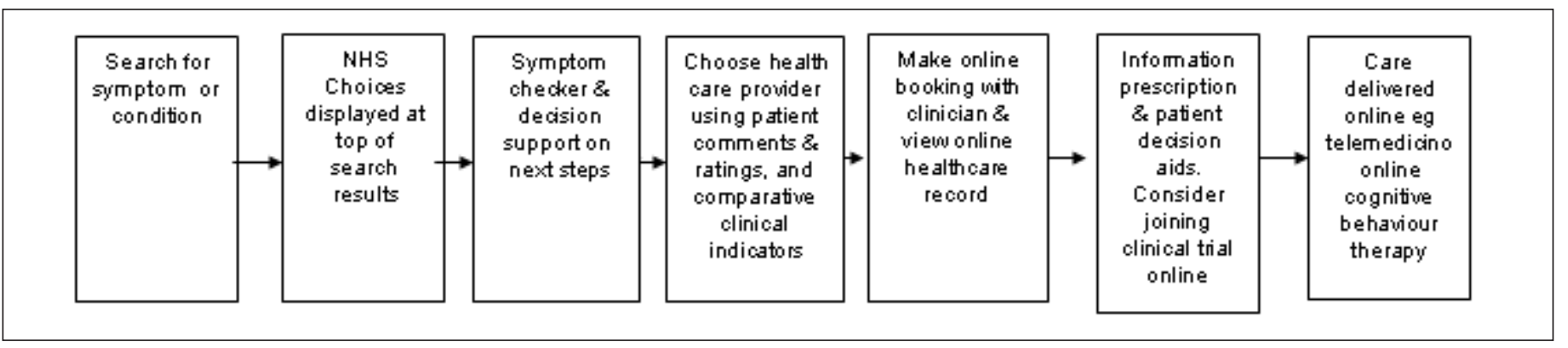

Fig. 1 Informing and involving on the patient journey 
Choices receives 15 million visits a month to content including:

- Self assessment symptom checker

- Patient decision aids for conditions with a range of treatment choices

- A-Z of 800 conditions \& treatments

- Clinical trials

- Live well healthy lifestyle content $\&$ interactive tools

- Behind the Headlines daily news analysis

- Over 600 videos

- Directories of services

- Comparative scorecards with clinical outcomes \& patient comments

Independent evaluation of the NHS Choices service suggests some positive outcomes in reducing demand on primary care for minor conditions. A study [15] carried out by Imperial College, London, asked patients whether they were more or less likely to visit their doctor after viewing information on NHS Choices. $60 \%$ said it makes no difference. However 37\% said it reduces number of visits and $3 \%$ said it increases. Reduced visits were most likely in people between 25 and 44 years of age, while increased visits were most likely in those between aged between 18 and 24. Three quarters of those reporting reduced visits were women.

It is sometimes suggested that internet use increases "cyberchondria", creating anxiety and making patients more likely to seek medical consultations. There was little evidence of this in the Imperial College study with only $3 \%$ of respondents reporting increased visits (some level of increased visits can be seen as a positive outcome if patients have become aware of symptoms which should receive attention). In the UK minor ailments make up fifth of all general practice appointments, account for $57 \mathrm{~m}$ GP visits a year and cost the NHS £2bn a year [16]. If as many as $37 \%$ of patients who use NHS Choices are enabled to self care appropriately and avoid a GP visit, the cost benefit would be considerable.

\section{Comparing and Choosing Services}

Information about the quality of care provided by health care organisations is increasingly available to patients online, enabling transparency, informing patient choice, and driving improvements in the quality of care [17]. This mirrors consumer experience in other areas of their lives where people are familiar with using "compare the market" type websites to choose between products and services.

NHS Choices has led the way in publishing comparative data on the performance of providers, publishing over 600 clinical indicators including mortality rates, readmission rates, hospital acquired infections etc. These are presented in simple to use tables so that patients can compare providers side by side, ranked by the criteria which are most important to them.

Patients want quantitative data about the performance of services, but they also want to know more about the experiences of patients like them in using services. Several initiatives in the UK enable patients to rate and comment on hospitals, general practices and other health care services. The national portal NHS Choices enables patients to do this, with 70,000 comments posted to date. If patients would prefer to leave their comment via a non-official route there are independent comment services, including $\mathrm{Pa}$ tient Opinion [18] and iWantGreatCare [19]. NHS Choices now aggregates comments from other good quality commenting sites and publishes these alongside comments posted on NHS Choices.

Patient comments are sometimes dismissed as subjective, emotive and unhelpful as a source of intelligence on the quality of services. However recent research in the UK [20] and the USA [21] is beginning to suggest that there is a correlation between patient feedback and more objective quantitative measures of quality of care. Re- search carried out by Imperial College, London found that positive recommendations of hospitals by patients were significantly associated with lower hospital mortality ratios and lower readmission rates. Better subjective ratings by patients were associated with lower MRSA and C.difficile infection rates. Where patients are posting about observing dirty wards, the quantified infection rates in the hospital are indeed high. It seems that the crowd may indeed be wise.

\section{Communicating and Transacting Online}

The accelerating pace of technical development means it will increasingly be possible for patients to interact with healthcare services in ways which are convenient, cost effective and reliable [22]. Increasingly general practices in the UK are providing patients with the opportunity to communicate with their doctor by secure email, and to make online appointment bookings at convenient times. Using the Choose and Book system to choose hospital outpatient appointments, requesting repeat prescriptions online, and receiving test results are all becoming commonplace.

However providing patients with easy access to their health record online lags a long way behind. There is a legal right of access in the UK but often this means nothing more than requesting a paper copy. Presently although over half of all general practices use IT systems which have the technical capability to provide people with electronic access to records, less than $1 \%$ offer this. This is despite the strong evidence to support the benefits of online access to records [23] with benefits including improved relationships between clinicians and patients, more informed and engaged patients, fewer errors, and improved ability for patients to manage their own condition. 


\section{Looking Forward: the Information Strategy for Health and Social Care in England}

The Department of Health in England is addressing these challenges and opportunities through a new information strategy for health and social care published in 2012 [24]. Key features of the strategy are:

- Information recorded once at the point of care and shared securely across care pathways, supported by consistent information standards

- Electronic access for patients to their healthcare record from 2015, starting with general practice records

- Full transparency where information held by government and health and care services about quality of care is openly and easily available to support choice and drive improvement

- Widespread use of modern technology to make health care more convenient, accessible and efficient

Fundamentally, this is about putting patients in control - enabling a culture of no decision about me without me.

\section{References}

1. Is online medical advice bad for your health? Which? November 2010

2. Health consumer study: the role of digital in patients' healthcare actions \& decisions Google/OTX December 2009 www.google.com/think/insights

3. The social life of health information Pew Research June 2009.

4. Getting patient information right, Which? September 2010.

5. Bessiere K, Pressman S, Kiesler S, Kraut R. Effects of internet use on health and depression: a longitudinal study. J Med Internet Res 2010;12(1):e6

6. O'Connor AM, Bennett CL, Stacey D, Barry M, Col NF, et al. Decision aids for people facing health treatment or screening decisions. Cochrane Database Syst Rev 2009 Jul 8;(3):CD001431.

7. Coulter A, Collins A. Making shared decision making a reality: no decision about me without me Kings Fund/Foundation for Informed Medical Decision Making; 2011.

8. Webb TL, Joseph J, Yardley L, Michie S. Using the internet to promote health behaviour change: a systematic review and meta-analysis. J Med Internet Res 2010; 12(1):e4.

9. Liberating the NHS: an information revolution. London: Department of Health; 2010

10. Department of Health: Liberating the NHS: an information revolution. Summary of consultation responses. London: Department of Health; 2011.

11. NHS Choices www.nhs.uk

12. Health consumer study: the role of digital in patients' healthcare actions \& decisions Google/OTX December 2009 www.google.com/think/insights

13. Information Standard. www.theinformationstandard. org

14. Information Prescriptions www.nhs.uk/planners/ yourhealth/pages/information.aspx
15. Murray J, Majeed A, Khan MS, Lee JT, Nelson P. Use of NHS Choices website for primary care consultations. JRSM Short Rep 2011; 2(7):56.

16. Workforce adults with minor ills overwhelming NHS The Times, March 162010

17. Boyce, T. Dixon, A. Fasolo, B \& Reutskaja, E Choosing a high quality hospital: the role of nudges, scorecard design and information. London: King's Fund, 2010.

18. Patient Opinion www.patientopinion.org.uk

19. iWantGreatCare www.iwantgreatcare.org

20. Greaves F, Pape UJ, King D, Darzi A, Majeed A, Wachter RM et al. Associations between web-based patient ratings and objective measures of hospital quality. Arch Intern Med 2012;172(5):435-6.

21. Gao GG, McCullough JS, Agarwal R, Jha AK. The changing landscape of physician quality reporting: analysis of patients' online ratings of their physicians over a 5-year period. J Med Internet Res 2012;14(1):e38.

22. Remote control: the patient practitioner relationship in the digital age NHS Confederation, 2011.

23. Pyper C, Amery J, Watson M, Crook C. Patients' experiences when accessing their online patient records in primary care. Br J Gen Pract 2004; 54(498):38-43.

24. The power of information: putting us in control of the health and care information we need. London: Department of Health; 2010.

\section{Correspondence to:}

Bob Gann

NHS Choices

Department of Health

Skipton House

Elephant and Castle

London SEI 6LH

United Kingdom

E-mail: bob.gann@dh.gsi.gov.uk 